\title{
PAPER
}

\section{Pharmacogenomics: marshalling the human genome to individualise drug therapy}

\section{W E Evans}

Gut 2003;52(Suppl II):ii 10-ii 18

Pharmacogenomics aims to identify the inherited basis for interindividual differences in drug response, and translate this to molecular diagnostics that can be used to individualise drug therapy. This review uses a number of published examples of inherited differences in drug metabolising enzymes, drug transporters, and drug targets (for example, receptors) to illustrate the potential importance of inheritance in determining the efficacy and toxicity of medications in humans. It seems that this field is at the early stages of developing a powerful set of molecular diagnostics that will have profound utility in optimising drug therapy for individual patients.

$\mathrm{P}$ harmacogenomics is a rapidly emerging field that aims to elucidate the genetic basis for interindividual differences in drug response, using genome wide approaches to identify genetic polymorphisms that govern an individual's response to specific drugs. ${ }^{1-4}$ As described in the initial reports from the human genome project, ${ }^{5}$ there are over 1.4 million single nucleotide polymorphisms (SNPs) in the human genome, with over 60000 of these residing in the coding region of human genes, and the number of SNPs will grow as more humans are studied. Some of these SNPs have already been associated with significant changes in the metabolism or effects of commonly used drugs and are beginning to make their way into clinical medicine as molecular diagnostics. ${ }^{2-4}$ For some genetic polymorphisms (for example, thiopurine S-methyltransferase (TPMT), cytochrome P4502D6), monogenic traits have a marked effect on drug disposition (for example, pharmacokinetic changes attributable to aberrant drug metabolism), and people who inherit the enzyme deficiency must be treated with substantially different doses of some affected drugs (for example, $5 \%-10 \%$ of the standard mercaptopurine or azathioprine dose in patients inheriting two mutant TPMT alleles).$^{6-8}$ Likewise, polymorphisms in drug targets (for example, $\beta_{2}$ adrenoceptor, 5-lipoxygenase) have been shown to change the sensitivity of patients to treatment with medications that interact with these targets (for example, $\beta$ agonists, zileuton), changing the pharmacodynamics of drug response. ${ }^{9}{ }^{10}$ Because most drug effects are determined by the interplay of several gene products that govern the pharmacokinetics and pharmacodynamics of medications, pharmacogenomics is increasingly focused
Lauderdale, Memphi

38101-0318, USA

william.evans@stjude.org on elucidating polygenic determinants of drug effects (fig l).

The potential importance of pharmacogenetics has been recognised for many years; clinical observations of inherited differences in drug effects were first reported in the $1950 \mathrm{~s}^{11-14}$ giving rise to the field of "pharmacogenetics", which has now been embraced by a broader spectrum of academia and industry, giving birth to "pharmacogenomics". The two terms are commonly used interchangeably to describe genetic determinants of drug disposition and response. There are now numerous examples establishing that interindividual differences can be attributed, at least in part, to polymorphisms in genes encoding drug metabolising enzymes, drug transporters and/or drug targets (for example, receptors, enzymes). ${ }^{1-4}$ While it is clear that many non-genetic factors influence the effects of medications, including a person's age, race, sex, organ function, concomitant therapy, disease severity, and drug interactions, inherited determinants of drug disposition and effects remain stable for a person's lifetime and can have marked effects, independent of the non-genetic factors.

The human genes involved in many pharmacogenetic traits have now been isolated, their molecular mechanisms elucidated, and their clinical importance more clearly defined (reviewed in references $\left.{ }^{1-4}\right)$. This review provides a number of examples of genetic polymorphisms that determine a person's response to drugs, and how this can be translated to clinical practice via molecular diagnostics (genotyping) to guide the selection of medications and drug doses that are optimal for the individual patient.

\section{POLYMORPHISMS IN GENES INFLUENCING DRUG DISPOSITION}

While pharmacogenetics began with a focus on drug metabolism, it has now been extended to all aspects of drug disposition, including a growing list of drug transporters that influence drug absorption, distribution, and excretion (table 1). ${ }^{1-4}$

\section{Drug metabolising enzymes}

There are over 30 families of drug metabolising enzymes in humans, ${ }^{1}$ and essentially all have genetic variants, many of which cause functional changes in the proteins encoded, and thereby change the metabolism of drugs.

Thiopurine methyltransferase (TPMT) and azathioprine, mercaptopurine, or thioguanine therapy

The genetic polymorphism of TPMT is one of the most well developed examples of clinical pharmacogenomics. TPMT catalyses the S-methylation of 


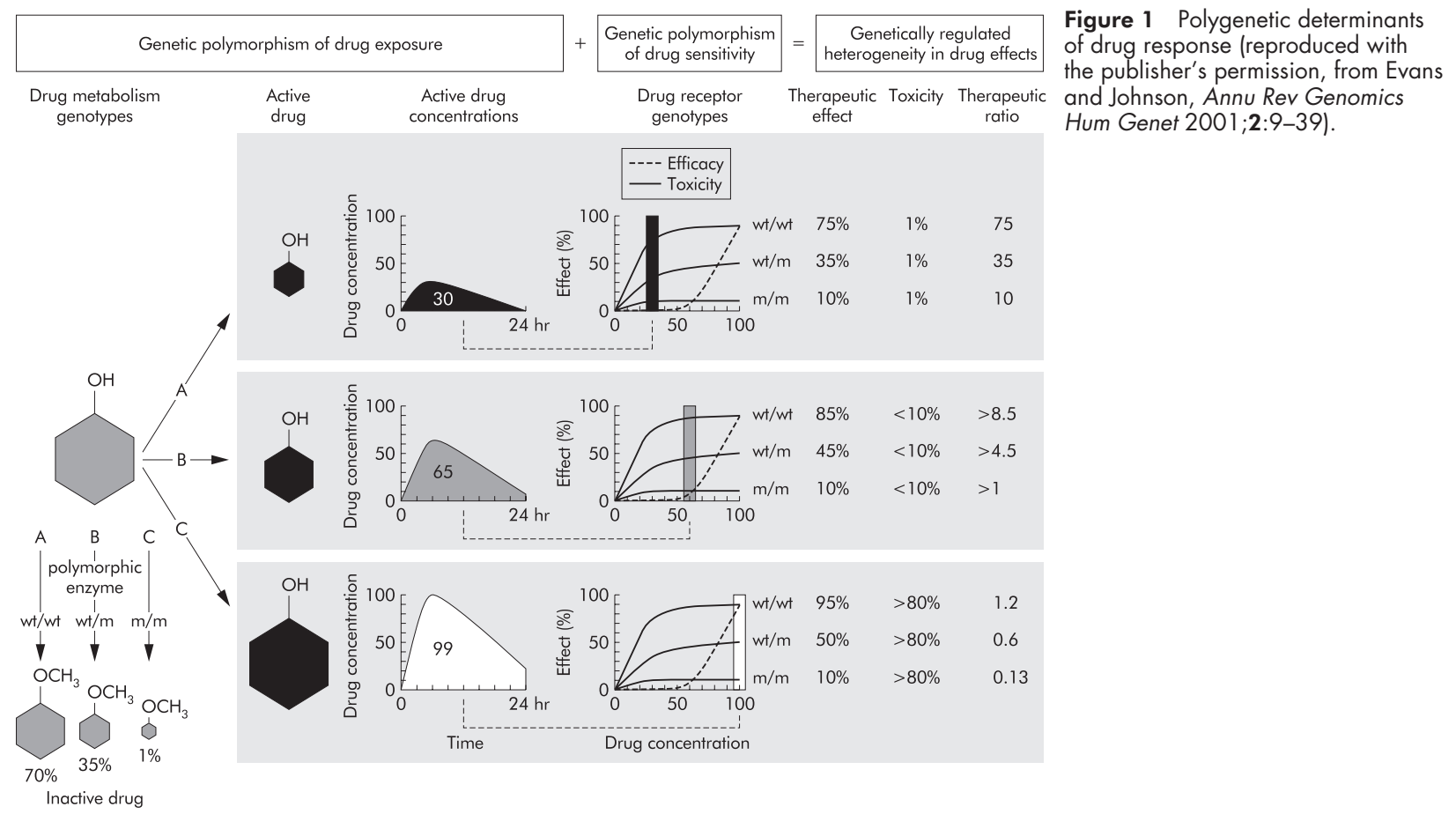

the thiopurine agents azathioprine, mercaptopurine and thioguanine. ${ }^{15}{ }^{16}$ These agents are commonly used for a diverse range of medical indications, including leukaemia, rheumatic diseases, inflammatory bowel disease, and solid organ transplantation. The principal cytotoxic mechanism of these agents is generally considered to be mediated via the incorporation of thioguanine nucleotides (TGN) into DNA. Thus, thiopurines are inactive prodrugs that require metabolism to TGN to exert cytotoxicity. This activation is catalysed by a multi-enzyme pathway, the first of which is hypoxanthine phosphoribosyltransferase (HPRT). Alternatively, these agents can be inactivated via oxidation by xanthine oxidase or methylation by TPMT. In haematopoietic tissues, xanthine oxidase is negligible, leaving TPMT as the only inactivation pathway. TPMT activity is highly variable and polymorphic in all large populations studied to date; about $90 \%$ of individuals have high activity, $10 \%$ have immediate activity, and $0.3 \%$ have low or undetectable enzyme activity. ${ }^{17}{ }^{18}$ Numerous studies have shown that TPMT deficiency patients are at high risk for severe, and sometimes fatal, haematological toxicity. ${ }^{6-8}$

The molecular basis for polymorphic TPMT activity has now been defined for most patients. While eight TPMT alleles have been identified, three alleles $(T P M T * 2, T P M T * 3 A, T P M T * 3 C)$ account for about $95 \%$ of intermediate or low enzyme activity cases (fig 2). ${ }^{16-20}$ All three alleles are associated with lower enzyme activity, because of increased rates of proteolysis of the mutant proteins. ${ }^{21}{ }^{22}$ The presence of TPMT*2, TPMT*3A, or $T P M T * 3 C$ is predictive of phenotype; patients with one wild type allele and one of these variant alleles (that, heterozygous) have intermediate activity and patients inheriting two variant alleles are TPMT deficient. ${ }^{17}{ }^{18}$ While most studies have used erythrocytes as a surrogate tissue for measuring TPMT activity, studies have also shown that TPMT genotype determines TPMT activity in leukaemia cells, as would be expected for germline mutations. ${ }^{23}$ By using allele specific PCR or PCR-RFLP to detect the three signature mutations in these alleles, a rapid and comparatively inexpensive assay is available to identify $>90 \%$ of all mutant alleles. ${ }^{17}$ In white populations, TPMT*3A is the most common mutant TPMT allele $(3.2 \%-5.7 \%$ of TPMT alleles), while TPMT*3C has an allele frequency of $0.2 \%-0.8 \%$ and $T P M T^{*} 2$ represents $0.2 \%-0.5 \%$ of TPMT alleles. ${ }^{16}$ Studies in white, African, and
Asian populations have demonstrated the broad utility of this approach, ${ }^{24-27}$ while revealing that the frequency of these mutant TPMT alleles differs among various ethnic populations. For example, East and West African populations have a frequency of mutant alleles similar to white populations, but all mutant alleles in the African populations are TPMT*3C. ${ }^{25}$ Among African-Americans, TPMT*3C is the most prevalent allele, but $T P M T * 2$ and $T P M T * 3 A$ are also found, reflecting the integration of white and African-American genes in the US population. ${ }^{24}$ In Asian populations, $T P M T{ }^{*} 3 C$ is the predominant mutant allele ( $100 \%$ of mutant alleles in published studies to date). ${ }^{16} 27$

Interest in TPMT pharmacogenetics has been fuelled by the finding that TPMT genotype identifies patients who are at risk of toxicity from mercaptopurine or azathioprine. Patients with a homozygous mutant or compound heterozygous genotype are at very high risk of developing severe haematopoietic toxicity, if treated with conventional doses of thiopurines. ${ }^{8}{ }^{28}$ More recent studies have now shown that patients who are heterozygous at the TPMT gene locus are at intermediate risk of dose limiting toxicity ${ }^{67}$ In a study of azathioprine for rheumatic disease, patients with wild type TPMT received treatment for a median 39 weeks without complications compared with a median of two weeks in patients heterozygous for one mutant TPMT allele and one wild type allele. ${ }^{6}$ A second study in Japanese rheumatic disease patients receiving azathioprine recently confirmed the importance of a heterozygous TPMT genotype for predicting systemic toxicity. ${ }^{29}$ A more quantitative analysis of mercaptopurine for childhood ALL found that TPMT deficient patients tolerated full doses of mercaptopurine for only $7 \%$ of weeks, whereas heterozygous and homozygous wild type patients tolerated full doses for $65 \%$ and $84 \%$ of scheduled weeks of treatment over the 2.5 years of treatment, respectively. ${ }^{6}$ The percentage of weeks in which mercaptopurine dose had to be decreased to prevent toxicity was $2 \%, 16 \%$, and $76 \%$ in wild type, heterozygous, and homozygous mutant individuals. ${ }^{6}$ Collectively, the above studies show that the influence of TPMT genotype on haematopoietic toxicity is most dramatic for homozygous mutant patients, but is also of clinical relevance for heterozygous individuals, which represent about $10 \%$ of patients treated with these drugs.

Prospective determination of functional TPMT status is of clinical utility to prevent mercaptopurine and azathioprine 


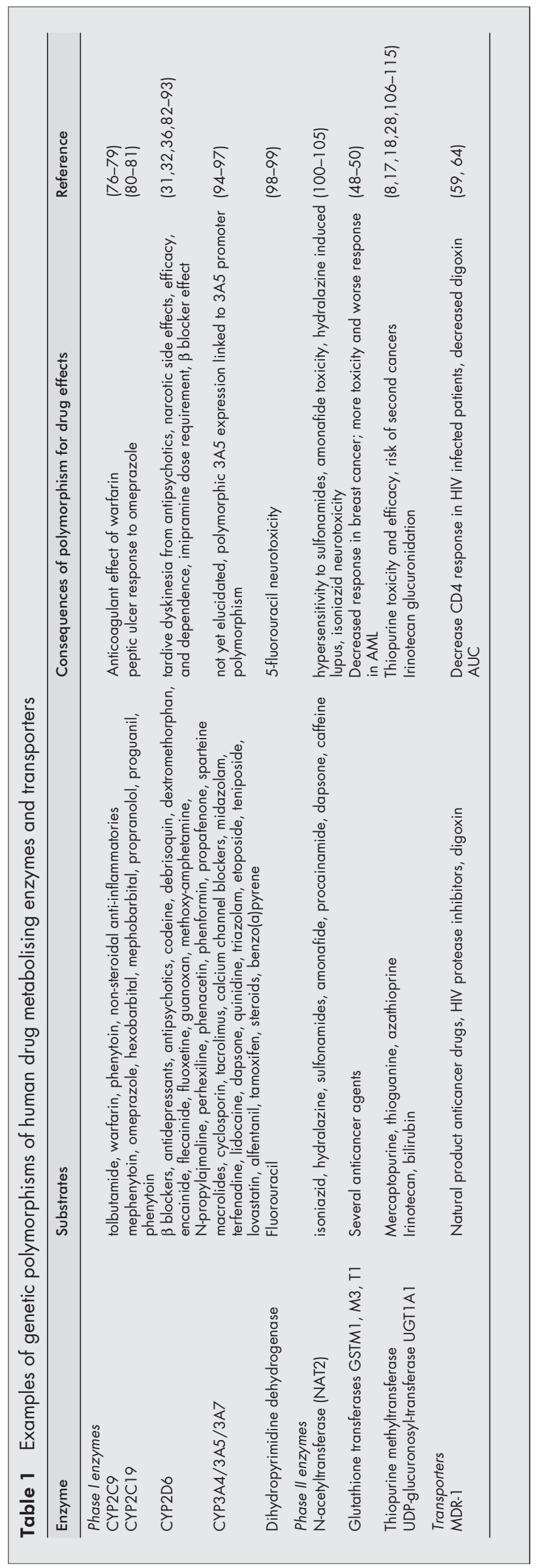

toxicity. TPMT genotyping is now available as a molecular diagnostic from reference laboratories, representing the first CLIA certified pharmacogenomics test for individualising drug treatment based on a patient's genotype. Patients with a "low methylator" status (homozygous mutant or compound heterozygote) may tolerate standard doses, but are at significantly greater risk of toxicity, often necessitating a lower dose of these drugs $\left(50 \%-80 \%\right.$ of standard doses).$^{68}$

\section{Cytochrome P450 enzymes}

The cytochrome P450 enzymes represent a large family of drug metabolising enzymes, ${ }^{1}$ catalysing the metabolism of more medications than any other family of enzymes. Debrisoquin hydroxylase (CYP2D6) is probably the most well characterised genetic polymorphism in cytochrome P450 enzymes, representing the first human polymorphic drug metabolising enzyme to be cloned and characterised at the molecular level. ${ }^{30}$ As was common in the pre-genomics era, its discovery was in part serendipitous, facilitated by the principal investigator's development of marked hypotension during participation in a pharmacokinetic study of debrisoquine, an antihypertensive. ${ }^{31}$ Family studies subsequently showed that he had inherited a deficiency in debrisoquin metabolism, an enzyme deficiency discovered independently with sparteine. ${ }^{32}$ Many drugs ( $>30$ ) were subsequently found to be substrates for CYP2D6, and this genetic polymorphism was documented in most populations worldwide, with pronounced racial differences in mutant allele frequencies. A large number of CYP2D6 SNPs, gene deletions and gene duplications have now been discovered, and concordance between genotype and phenotype has been well established for many drug substrates. ${ }^{33}$ CYP2D6 deficiency can result in either exaggerated drug effects when CYP2D6 is the major inactivation pathway (for example, tricyclic antidepressants, fluoxetine) or diminished effects when CYP2D6 is required for activation (for example, codeine). ${ }^{34}$ Moreover, gene duplication of CYP2D6 leads to inheritance of an "ultrarapid metaboliser" phenotype, which has been linked to treatment failure for some antidepressant and antipsychotic drugs. ${ }^{36}{ }^{37}$

Genetic polymorphisms do not always translate into distinct phenotypic differences in drug metabolism in population studies, exemplified by a common polymorphism in the P450 enzyme CYP3A5 ${ }^{38}$ The CYP3A5 protein is expressed in only about half of African-Americans and about $20 \%$ of the white population, and those people who express both CYP3A5 and CYP3A4 have higher total CYP3A enzyme activity, which translates to higher rates of drug clearance when medications are metabolised by both CYP3A4 and CYP3A5 as the major route of elimination. Recently, the genetic basis for polymorphic CYP3A5 expression was discovered; a SNP located over $>1600$ bp into intron 3 of CYP3A5 (and more than 200 nucleotides 5' of wild-type exon 4 splice site), leading to insertion of $>130$ nucleotides of intron 3 sequence into the mRNA. This additional mRNA sequence introduces an early stop codon that encodes a truncated non-functional CYP3A5 protein. For drugs that are equally metabolised by both, the net rate of metabolism is the sum of CYP3A4 and CYP3A5, partially masking the genetic polymorphism of CYP3A5 (fig 3). The CYP3A pathway of drug elimination is also influenced by SNPs in the CYP3A4 gene, which changes the activity of this enzyme for some substrates but not others. ${ }^{39}$ Discovery of the genetic basis for CYP3A5 deficiency, ${ }^{38}$ makes it possible to easily identify those patients who express CYP3A5 based on their genotype, but the clinical importance of these CYP3A genetic polymorphisms has not been fully elucidated to date.

Glutathione S-transferases

Glutathione is conjugated to many electrophiles, including several medications and their potentially damaging oxidative 


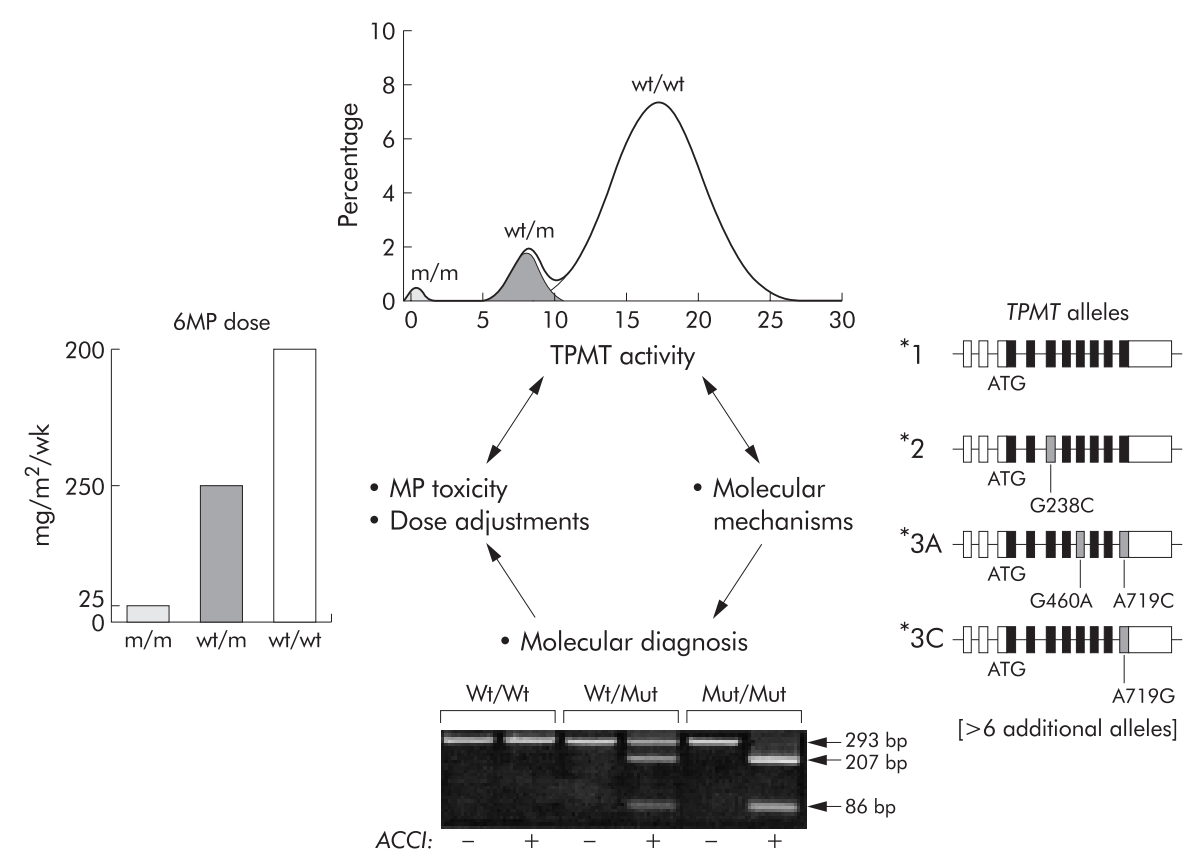

Figure 2 Genetic polymorphism of thiopurine methyltransferase and its importance in determining response to thiopurine medications (azathioprine, mercaptopurine, and thioguanine) (reproduced with publisher's permission, from Krynetski and Evans Am J Hum Genet 1998;63:11-16).

(9)

ACCl:

metabolites. ${ }^{40}{ }^{41}$ Conjugation with glutathione generally inactivates these reactive moieties, ${ }^{42}$ although this is not always the case. These conjugation reactions are catalysed by a family of human glutathione S-transferases (GST), and the human genes encoding these enzymes are highly polymorphic, with about $50 \%$ and $25 \%$ of most populations having a complete deletion of GST-M1 and GST-TI, respectively, rendering them void of these enzyme activities. As is typical for many gene polymorphisms, there are important racial and ethnic differences in the frequencies of gene deletions in different human populations. Other GSTs, (that is, GST-PI and GST-A), are also subject to genetic polymorphisms, and these have been implicated in resistance to several anti-anticancer agents. ${ }^{41} 434$

Several studies have reported associations between GST polymorphisms and the efficacy and/or toxicity of cancer chemotherapy. High GST activity has been associated with resistance to anticancer agents, consistent with the association of inherited GST deficiencies with a decreased risk of haematological relapse ${ }^{45} 47$ and central nervous system relapse $^{4648}$ and to improved prednisone response $e^{474}$ in children treated with combination chemotherapy for acute lymphoblastic leukaemia. Similarly, inheriting a GST-P1 allele coding for the Ile ${ }^{105} \mathrm{Val}$ amino acid substitution has been associated with improved overall breast cancer survival, compared with patients who had at least one wild type GST-P1 allele. ${ }^{48} 50$ In breast cancer patients, deletion of either GST-MI or GST-T1 was associated with improved survival, with further improvement in outcome if both genes were deleted ${ }^{49}{ }^{51}$ In contrast, in patients with acute myeloid leukaemia treated with high doses of combination chemotherapy, the homozygous GST-T1 deletion was associated with a higher risk of toxic death during remission, ${ }^{50}$ most probably because such patients could not tolerate intensive chemotherapy due to the absence of detoxifying GST enzymes. Together, these studies in breast cancer and AML patients illustrate that the importance of a genetic polymorphism in drug metabolism may differ based on the nature and intensity of the treatment regimen being prescribed. When treatment intensity is comparatively modest, leading to potential under treatment of some patients, then inheriting an enzyme deficiency can increase the exposure to drugs that are substrates, and thereby increase their efficacy. Conversely, when drugs are being dosed at levels that are near those that produce toxicity (common in AML), then inheritance of an enzyme deficiency can lead to a worse outcome because of greater toxicity.

\section{Drug transport proteins}

Transport proteins play an important part in human physiology and pharmacology, providing protective functions (for example, blood-brain barrier), contributing to critical cellular processes (for example, biliary excretion), and influencing the absorption of drugs and other compounds from the small intestine. The ATP binding cassette (ABC) family of membrane transporters, ${ }^{51}$ comprise an extensively studied group of transporters influencing drug disposition and effects. P-glycoprotein (PGP), a member of the ABC family, is involved in the energy dependent efflux of substrates, including bilirubin, several anticancer drugs, cardiac glycosides, immunosuppressive agents, glucocorticoids, HIV-1 protease inhibitors, and many other drugs. ${ }^{51-55}$ Expression of the PGP gene $(A B C B 1$, also names $M D R I)$ in normal tissue suggests that it is involved in excreting drugs and their metabolites into urine, bile, and the intestinal lumen..$^{54-58}$ At the blood-brain barrier, PGP in the choroids plexus limits brain accumulation of many drugs, including cyclosporin A, dexamethasone, digoxin, domperidone, loperamide, and vinblastine (table 2). ${ }^{55} 57$

PGP expression differs markedly among individuals, ${ }^{58}{ }^{60}$ the molecular basis of which has not been fully elucidated. Recently, a synonymous SNP in exon 26 (3435C > T), was reported to be associated with duodenal PGP protein expression; patients homozygous for the $\mathrm{T}$ allele had more than twofold lower duodenal PGP expression compared with patients with CC genotypes. ${ }^{58}$ Clinical pharmacokinetic studies of digoxin, a PGP substrate, demonstrated significantly higher bioavailability in patients with the CC genotype. ${ }^{59}$ As is common for most genetic traits, there are considerable ethnic differences in the frequency of the $3435 \mathrm{C}>\mathrm{T}$ SNP; the TT genotype was found in $0 \%-6 \%$ of black African and African-Americans, $20-47 \%$ of Asians, and 24\%-36\% of the white population..$^{60-62}$ However, the $3435 \mathrm{C}>\mathrm{T}$ SNP is in linkage disequilibrium with a non-synonymous SNP in exon 21 (1236C $>$ T, Ala893Ser) that has been shown to change PGP function, ${ }^{63}$ so it is unclear whether the $3435 \mathrm{C}>\mathrm{T}$ SNP is of functional importance or just in linkage with the functionally important SNP in $A B C B 1$. 

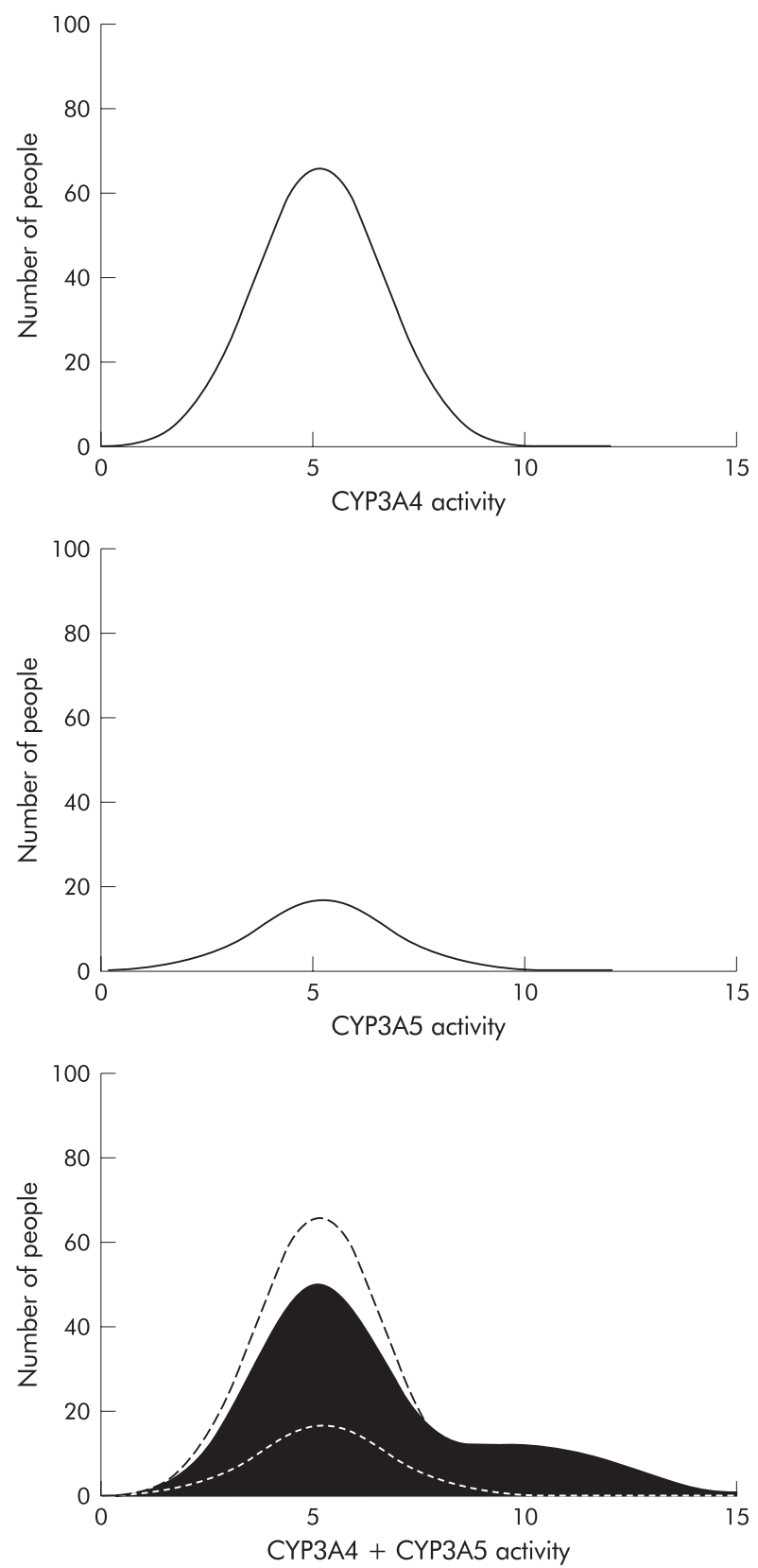

Figure 3 The cytochromes P450 CYP3A4 and CYP3A5 genetic polymorphism. The top panel depicts the distribution of CYP3A4 activity in the white population, assuming that $100 \%$ of individuals express CYP3A4, with a 10-fold range of activity in the population. The middle panel depicts CYP3A5 expression, assuming that $25 \%$ of the white population express $3 A 5$, with a 10 -fold range of activity. The bottom panel depicts the CYP3A4 and CYP3A5 distributions (dashed lines) and the composite distribution for drugs metabolised equally well by both enzymes.

In a recent study, the $A B C B 13435 \mathrm{C}>\mathrm{T}$ polymorphism was found to be associated with significant differences in nelfinavir and efavirenz pharmacokinetics in HIV infected patients, and recovery of CD4 count was significantly greater and more rapid in patients with the TT genotype than patients with either CT or CC genotypes. Of all variables evaluated, only $A B C B 1$ genotype and baseline HIV RNA copy number were significant predictors of CD4 recovery. ${ }^{64}$ Unfortunately, these investigators did not genotype for the $A B C B 1$ 1236C > T SNP, so it remains unclear whether the $3435 \mathrm{C}>\mathrm{T}$ is causative or in linkage with the causative SNP. This is the first evidence that a host genetic marker can predict immune recovery after ini- tiation of antiretroviral treatment, suggesting a potential strategy to individualise HIV therapy, if these findings can be independently verified.

\section{GENETIC POLYMORPHISM OF DRUG RECEPTORS AND OTHER TARGETS}

Genetic variation in drug targets (for example, receptors) can have a profound effect on drug effects, with over 25 examples already identified, including the $\beta_{2}$ adrenoceptor and response to $\beta_{2}$ agonists, ${ }^{956668}$ angiotensin converting enzyme and renoprotective effects of ACE inhibitors, ${ }^{66}$ apolipoprotein E and response to HMG-Co reductase inhibitors ("statins") ${ }^{67}$ and more than 20 other examples (reviewed in references ${ }^{1-3}$ ). The potential importance of these genetic polymorphisms is exemplified in this review by the $\beta_{2}$ adrenoceptor.

Genetic polymorphism of the $\beta_{2}$ adrenoceptor exemplifies a well characterised and clinically relevant polymorphism in a drug target. ${ }^{65}$ The $\beta_{2}$ adrenoreceptor is a G protein coupled receptor that interacts with various medications and endogenous catecholamines. These receptors are widely expressed in humans and play an important part in regulating cardiac, vascular, pulmonary, and metabolic functions. ${ }^{95}$ Studies of such physiological functions of the human $\beta_{2}$ adrenoceptor have revealed substantial interpatient differences in receptor function and responsiveness to stimulation. In the heart, activation of $\beta_{2}$ adrenoceptor results in an increased rate and force of cardiac muscle, whereas $\beta_{2}$ adrenoceptor stimulation in the lungs acts to relax airway smooth muscle. Effects on lipolysis in subcutaneous fat have also been reported, mediated putatively through regulation of lipid mobilisation, energy expenditure, and glycogenolysis. Insights to the molecular basis for inherited differences in the $\beta_{2}$ adrenoceptor have been illuminated by the discovery of several SNPs in the B2AR gene, and their association with altered expression, down regulation, or coupling of the receptor. ${ }^{65}$ Single nucleotide polymorphisms resulting in an Arg to Gly amino acid change at codon 16 and a Gln to Glu change at codon 27 are comparatively common (allele frequency $=0.4-0.65$ ) and are being extensively investigated for their clinical importance. Studies of agonist mediated vasodilatation and desensitisation have begun to dissect the relative contribution of the codon 16 and codon 27 mutations." Subjects who were homozygous for Arg 16 had nearly complete desensitisation after continuous infusion of isoproterenol, with venodilatation decreasing from $44 \%$ at baseline to $8 \%$ at 90 minutes. Homozygous Glyl6 patients had no significant change in venodilatation, regardless of their codon 27 sequence. Polymorphism at codon 27 was also of functional relevance, as patients homozygous for Glu27 had higher maximal venodilatation in response to isoproterenol $(86 \%)$ than observed in subjects with the codon 27 Gln genotype, regardless of codon 16 sequence. ${ }^{9}$

These results are consistent with the reported effects of B2AR genotype on pulmonary response to acute or chronic $\beta$ agonist therapy. The $\mathrm{FEV}_{1}$ response to a single dose of oral albuterol was more that sixfold higher in patients with an Arg/Arg genotype at codon 16 compared with Gly/Gly patients, even though similar plasma drug concentrations were achieved. ${ }^{68}$ Interestingly, the influence of this genotype changed when long term inhaled $\beta$ agonist therapy was used. An Arg/Arg genotype in patients on regularly scheduled $\beta$ agonist therapy resulted in a gradual decline in morning peak expiratory flow (AM PEF) over the 16 weeks of evaluation, while no change in this parameter was observed in patients with a Gly/Gly genotype ${ }^{69}$ In addition, AM PEF deteriorated substantially after cessation of treatment in the Arg/Arg patients receiving regularly scheduled inhaled $\beta$ agonist therapy, but not in patients with a Gly/Gly genotype. ${ }^{69}$ There was no evidence that the codon 27 polymorphism influenced AM PEF in these patients. These data suggest that patients with a B2AR Arg/Argl6 genotype may be at risk for 


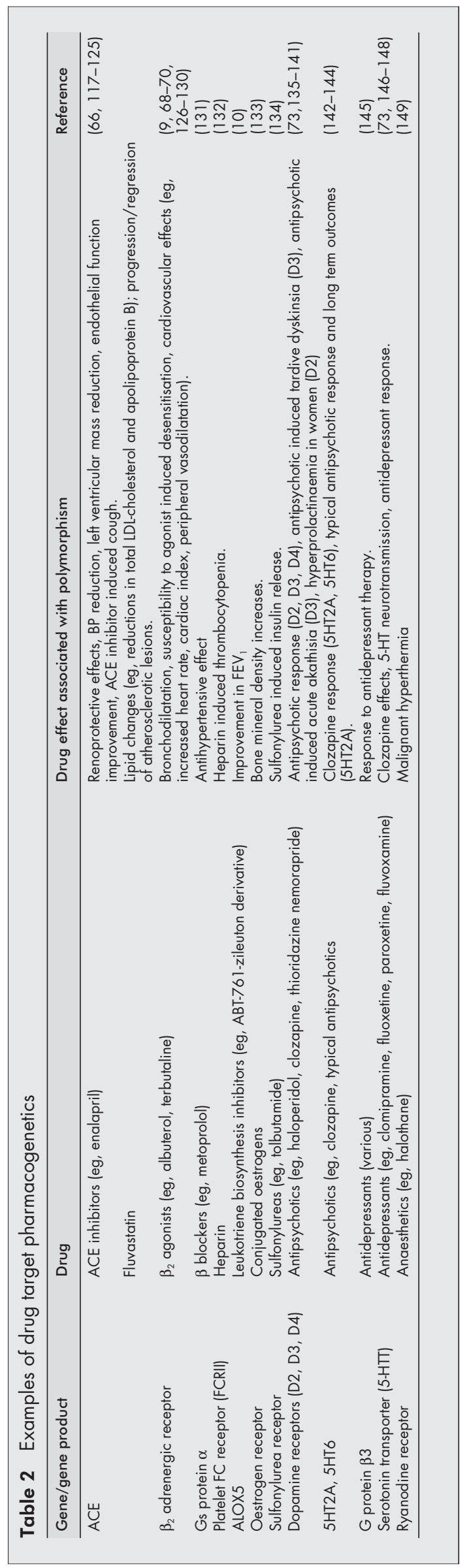

deleterious or non-beneficial effects of regularly scheduled inhaled $\beta$ agonist therapy and may be candidates for alternative treatment or dosing schedules and/or earlier initiation of anti-inflammatory drugs. These results are consistent with the data described above for desensitisation of the $\beta 2$ adrenoceptor in patients with a codon 16 Arg/Arg genotype. ${ }^{9}$ Although the codon 27 polymorphism does not seem to have a significant effect on inhaled $\beta$ agonist therapy, an association between the codon $16 \mathrm{Gln} / \mathrm{Gln}$ genotype and an increased incidence of obesity has been observed. This relation seemed to be more prominent in men and could be overcome with exercise.

These B2AR SNPs are not the only SNPs found in the $\beta_{2}$ adrenoceptor, with at least 13 distinct SNPs identified to date, leading to evaluation of B2AR haplotype structure compared with individual SNPs in determining receptor function and pharmacological response. ${ }^{70}$ While over 8000 B2AR haplotypes are theoretically possible, only 12 distinct haplotypes were observed among 77 subjects of various ethnic origin. ${ }^{70}$ Importantly, clinical evaluation of $\beta$ agonist therapy in asthma patients revealed a better association of B2AR haplotype and bronchodilator response, than observed with any B2AR SNP alone. ${ }^{70}$ This is not surprising, as haplotype structure is often a better predictor of phenotypic consequences, which has led to the development of various methods to determine haplotype structure, some of which are comparatively simple to perform. ${ }^{71}$ It is likely that as more pharmacogenomic studies are conducted, haplotype structure will commonly emerge as the most informative genetic determinant of drug response.

\section{MOLECULAR DIAGNOSTICS FOR OPTIMISING DRUG THERAPY}

There is clearly great potential for pharmacogenomics to yield important new molecular diagnostics that will become routine clinical laboratory tests, by which physicians and pharmacists select drugs and doses for individual patients. Instead of using empirical treatment algorithms, pharmacogenomics can provide patient specific diagnostics to optimise drug treatment. Using the amount of DNA that can be isolated from a few millilitres of blood, it is possible to determine thousands of genotypes, and methodology is improving so rapidly that it will soon be straightforward to perform these tests in high throughput, automated systems, screening for thousands of SNPs in one test. This will be necessary, because most drug effects are polygenic in nature ${ }^{172}$ so treatment decisions will be based on a panel of SNPs. These genotyping results will not be reported as a list of SNPs, rather they will be interpreted for the clinician according to the patient's diagnosis and treatment options. These new tests will not replace the more conventional biochemical tests that are currently used to assess organ function and disease status, rather they will provide additional tools for individualising and optimising drug therapy. Obviously, genotyping will not eliminate the need for follow up assessment of response, compliance with treatment, and other variables that influence treatment outcome. However, pharmacogenomics will make it increasingly possible to select the medications and doses that are optimal for each person, thereby improving efficacy and reducing toxicity. ${ }^{13}{ }^{74}$ In this regard, it has been recently reported ${ }^{73}$ that among 27 drugs for which adverse events are frequently reported, a significantly higher percentage are metabolised by a polymorphic enzyme (59\%) compared with randomly selected drugs $(7 \%-22 \%)$. A substantial amount of work remains to be done, before the full clinical utility of pharmacogenomics can be fully appreciated and realised. While there are currently numerous examples that illustrate the potential, we are in the early days of deciphering the importance of genetic polymorphisms in determining drug response. Critical issues going forward include the fact that most drug effects are polygenic in nature, that haplotype structure is often more 
informative than individual SNPs, and that functionally important polymorphisms can reside outside the coding or regulatory regions of genes. It is also important to recognise that clearly defined and objectively measured end points (that is, phenotypes) are essential to elucidate genotype-phenotype relations. In this regard, prospective clinical trials represent the ideal context within which pharmacogenomics of drug response are most likely to be elucidated. If done properly, ongoing research will change the practice of medicine and pharmacy, such that using genotype to individualise drug therapy will become the norm.

\section{ACKNOWLEDGEMENT}

Supported in part by the following NIH grants; R37 CA36401, R01 CA78224, U01 GM61393, U01 GM61394, Cancer Center support grants CA21765 and CA091842, by a Center of Excellence grant from the State of Tennessee, and by American Lebanese Syrian Associated Charities.

The author thanks Drs Howard McLeod, Julie Johnson, Eugene Krynetski, and Mary Relling for their many contributions and helpful suggestions during the preparation of this review.

\section{REFERENCES}

1 Evans WE, Relling MV. Pharmacogenomics: translating functional genomics into rational therapeutics. Science 1999-286:487-91.

2 Evans WE, Johnson JA. Pharmacogenomics: The inherited basis for interindividual differences in drug response. Ann Rev Genomics Hum Genet $2001 ; 2: 9-39$.

3 McLeod HL, Evans WE. Pharmacogenomics: unlocking the human genome for better drug therapy. Ann Rev Pharmacol Toxicol 2001;41:101-21.

4 Roses, AD. Pharmacogenetics. Hum Mol Genet 2001;10:2261-7.

5 Sachidananandam R, Weissman D, Schmidt SC, et al. The International SNP Map Working Group. A map of human genome sequence variation containing 1.42 million single nucleotide polymorphisms. Nature 2001; 409:928-33.

6 Relling MV, Hancock ML, Rivera GK, et al. Mercaptopurine therapy intolerance and heterozygosity at the thiopurine S-methyltransferase gene locus. J Natl Cancer Inst 1999;23: 1983-5.

7 Black AJ, McLeod HL, Capell HA, et al. Thiopurine methyltransferase genotype predicts therapy-limiting severe toxicity from azathioprine. Ann Intern Med. 1998;129:716-18

8 Evans WE, Hon YY, Bomgaars L,et al. Preponderance of thiopurine S-methyltransferase deficiency and heterozygosity among patients intolerant to mercaptopurine or azathioprine. J Clin Oncol 2001;19:2293-301

9 Dishy V, Sofowora GG, Xie HG, et al. The effect of common polymorphisms of the beta2-adrenergic receptor on agonist-mediated vascular desensitization. N Engl J Med 2001;14:1030-5.

10 Drazen JM, Yandava CN, Dube L, et al. Pharmacogenetic association between ALOX5 promoter genotype and the response to anti-asthma treatment. Nat Genet 1999;22:168-70.

11 Kalow W. Familial incidence of low pseudocholinesterase level. Lancet 1956;ii:576

12 Carson PE, Flanagan CL, Ickes CE, et al. Enzymatic deficiency in primaquine-sensitive erythrocytes. Science 1956;124:484.

13 Hughes HB, Biehl JP, Jones AP, et al. Metabolism of isoniazid in man as related to occurrence of peripheral neuritis. Am Rev Tuberc 1954;70:266.

14 Evans DAP, Manley KA, McKusick VA. Genetic control of isoniazid metabolism in man. BN 1960;2:485.

15 Krynetski GY, Evans WE. Pharmacogenetics of cancer chemotherapy: getting personal (mini-review). Am J Hum Genet 1998;63:11-16.

16 McLeod HL, Krynetski EY, Relling MV, et al. Genetic polymorphism of thiopurine methyltransferase and its clinical relevance for childhood acute lymphoblastic leukemia. Leukemia 2000;14:567-72.

17 Yates CR, Krynetski EY, Loennechen T, et al. Molecular diagnosis of thiopurine S-methyltransferase deficiency: genetic basis for azathioprine and mercaptopurine intolerance. Ann Intern Med 1997;126:608-14.

18 Otterness D, Szumlanski C, Lennard L, et al. Human thiopurine methyltransferase pharmacogenetics: gene sequence polymorphisms. Clin Pharmacol Ther 1997;62:60-73.

19 Krynetski EY, Schuetz JD, Galpin AJ, et al. A single point mutation leading to loss of catalytic activity in human thiopurine S-methyltransferase. Proc Natl Acad Sci USA 1995;92:949-53.

20 Tai H-L, Krynetski EY, Yates CR, et al. Thiopurine S-methyltransferase deficiency: two nucleotide transitions define the most prevalent mutant allele associated with loss of catalytic activity in Caucasians. Am J Hum Genet 1996:58:694-702

21 Tai H-L, Krynetski EY, Schuetz EG, et al. Enhanced proteolysis of thiopurine S-methyltransferase (TPMT) encoded by mutant Aalleles in humans (TPMT*3A, TPMT*2): mechanisms for the genetic polymorphism of TPMT activity. Proc Natl Acad Sci USA 1997;94:6444-9.

22 Tai H-L, Fessing M, Bonten EJ, et al. Enchanced proteasoma degradation of mutant human thiopurine S-methyltransferase (TPMT) in mammalian cells: mechanism for TPMT protein deficiency inherited by TPMT*2, TPMT*3A, TPMT*3B or TPMT*3C. Pharmacogenetics 1999;9:641-50

23 McLeod, HL, Relling MV, Liu Q, et al. Polymorphic thiopurine methyltransferase in erythrocytes is indicative of activity in leukemic blasts from children with acute lymphoblastic leukemia. Blood 1995;85: 1897-902.

24 Hon YY, Fessing MY, Pui CH, et al. Polymorphism of the thiopurine S-methyltransferase gene in African-Americans. Hum Mol Genet 1999;8:371-6.

25 Ameyaw MM, Collie-Duguid ES, Powrie RH, et al. Thiopurine methyltransferase alleles in British and Ghanaian populations. Hum Mol Genet 1999;8:367-70

26 Mcleod HL, Pritchard SC, Githang'a J, et al. Ethnic differences in thiopurine methyltransferase pharmacogenetics:evidence for allele specificity in Caucasian and Kenyan individuals. Pharmacogenetics 1999:6:773-6.

27 Kubota T, Chiba K. Frequencies of thiopurine S-methyltransferase mutan alleles (TPMT*2, ${ }^{*} 3 \mathrm{~A},{ }^{*} 3 \mathrm{~B}$ and ${ }^{*} 3 \mathrm{C}$ ) in 151 healthy Japanese subjects and the inheritance of TPMT* $3 \mathrm{C}$ in the family of a propositus. Br J Clin Pharmacol 2001;51:475-7.

28 Evans WE, Horner M, Chu YQ, et al. Altered mercaptopurine metabolism, toxicity and dosage requirements in a thiopurine methyltransferase-deficient child with acute lymphocytic leukemia. J Pediatr 1991;119:985-9.

29 Kumagai K, Hiyama K, Ishioka S, et al. Allelotype frequency of the thiopurine methyltransferase (TPMT) gene in Japanese. Pharmacogenetics $2001 ; 3: 275-8$

30 Gonzalez FJ, Skoda RC, Kimura S, et al. Characterization of the common genetic defect in humans deficient in debrisoquine metabolism. Nature 1988;331:442-6.

31 Mahgoub A, Idle JR, Dring LG, et al. Polymorphic hydroxylation of Debrisoquine in man. Lancet 1977; ii:584-6.

32 Eichelbaum M, Bertilsson L, Sawe J, et al. Polymorphic oxidation of sparteine and debrisoquine: related pharmacogenetic entities. Clin Pharmacol Ther 1982;31:184-6.

33 Ingelman-Sundberg $\mathbf{M}$, Oscarson M, McLellan RA. Polymorphic human cytochrome P450 enzymes: an opportunity for individualized drug treatment. Trends Pharm Sci 1999;20:342-9.

34 Dahl ML, Johansson I, Palmertz MP, et al. Analysis of the CYP2D6 gene in relation to debrisoquin and desipramine hydroxylation in a Swedish population. Clin Pharmacol Ther 1992;51:12-17.

35 Sindrup SH, Brosen K. The pharmacogenetics of codeine hypoalgesia. Pharmacogenetics 1995; 5:335-46.

36 Johansson I, Lundqvist E, Bertilsson L, et al. Inherited amplification of an active gene in the cytochrome P450 CYP2D locus as a cause of ultrarapid metabolism of debrisoquine. Proc Natl Acad Sci USA 1993;90:1 1825-9.

37 Meyer UA. Pharmacogenetics: the slow, the rapid, and the ultrarapid. Proc Natl Acad Sci USA 1994:91:1983-4.

38 Kuehl P, Zhang J, Lin Y, et al. Sequence diversity in CYP3A promoters and characterization of the genetic basis for polymorphic CYP3A5 expression. Nat Genet 2001;27:383-91

39 Sata F, Sapone A, Elizondo G, et al. CYP3A4 allelic variants with amino acid substitutions in exons 7 and 12: evidence for an allelic variant with altered catalytic activity. Clin Pharmacol Ther 2000;67:48-56.

40 Ketterer B. Protective role of glutathione and glutathione transferases in mutagenesis and carcinogenesis. Mutat Res 1988;202:343-61.

41 Tew KD. Glutathione-associated enzymes in anticancer drug resistance. Cancer Res 1994:54:4313.

42 Seidegard J, Ekstrom G. The role of human glutathione transferases and epoxide hydrolases in the metabolism of xenobiotics. Environ Health Perspect 1997; 105:791-9.

43 Hayes JD, Strange RC. Potential contribution of the glutathione S-transferase supergene family to resistance to oxidative stress. Free Radic Res 1995;22:193-207.

44 Ban N, Takahashi Y, Takayama T, et al. Transfection of glutathione S-transferase (GST)-pi antisense complementary DNA increases the sensitivity of a colon cancer cell line to adriamycin, cisplatin, melphalan, and etoposide. Cancer Res 1996:56:3577-82.

45 Stanulla M, Schrappe M, Brechlin AM, et al. Polymorphisms within glutathione S-transferase genes (GSTM1, GSTT1, GSTP1) and risk of relapse in childhood B-cell precursor acute lymphoblastic leukemia: case-control study. Blood 2000;95:1222-8.

46 Chen $\mathrm{CL}$, Liu Q, Pui $\mathrm{CH}$, et al. Higher frequency of glutathione S-transferase deletions in black children with acute lymphoblastic leukemia. Blood 1997;89:1701-7.

47 Anderer G, Schrappe M, Brechlin AM, et al. Polymorphisms within glutathione $\mathrm{S}$-transferase genes and initial response to glucocorticoids in childhood acute lymphoblastic leukaemia. Pharmacogenetics 2000;10:715-26.

48 Sweeney C, McClure GY, Fares MY, et al. Association between survival after treatment for breast cancer and glutathione S-transferase $\mathrm{Pl}$ lle 105Val polymorphism. Cancer Res 2000;60:5621-4.

49 Ambrosone CB, Sweeney C, Coles BF, et al. Polymorphisms in glutathione S-transferases (GSTM1 and GSTT1) and survival after treatment for breast cancer. Cancer Res 2001;61:7130-5.

50 Davies SM, Robison LL, Buckley JD, et al. Glutathione S-transferase polymorphisms and outcome of chemotherapy in childhood acute myeloid leukemia. J Clin Oncol 2001;19:1279-87.

51 Borst P, Evers R, Kool M, Wiinholds J, et al. A family of drug transporters: the multidrug resistance-associated proteins. J Natl Cancer Inst 2000;92:1295-302. 
52 Choo EF, Leake B, Wandel C, et al. Pharmacological inhibition of P-glycoprotein transport enhances the distribution of HIV-1 protease inhibitors into brain and testes. Drug Metab Dispos 2000;28:655-60.

53 Brinkmann U, Roots I, Eichelbaum M. Pharmacogenetics of the human drug-transporter gene MDR 1: impact of polymorphisms on pharmacotherapy. Drug Discov Today 2001;6:835-9.

54 Fojo AT, Ueda K, Slamon DJ, et al. Expression of a multidrug-resistance gene in human tumors and tissues. Proc Natl Acad Sci USA 1987;84:265-9

55 Rao VV, Dahlheimer JL, Bardgett ME, et al. Choroid plexus epithelial expression of MDR 1 P glycoprotein and multidrug resistance-associated protein contribute to the blood-cerebrospinal-fluid drug-permeability barrier. Proc Natl Acad Sci USA 1999;96:3900-5.

56 Thiebaut F, Tsuruo T, Hamada H, et al. Cellular localization of the multidrug-resistance gene product $\mathrm{P}$-glycoprotein in normal human tissues. Proc Natl Acad Sci USA 1987;84:7735-8.

57 Schinkel AH, Wagenaar E, Mol CA, van Deemter L. P-glycoprotein in the blood-brain barrier of mice influences the brain penetration and pharmacological activity of many drugs. J Clin Invest 1996;97:251724.

58 Hoffmeyer S, Burk O, von Richter $O$, et al. Functional polymorphisms of the human multidrug-resistance gene: multiple sequence variations and correlation of one allele with P-glycoprotein expression and activity in vivo. Proc Natl Acad Sci USA 2000:97:3473-8.

59 Sakaeda T, Nakamura T, Horinouchi M, et al. MDR 1 genotype-related pharmacokinetics of digoxin after single oral administration in healthy Japanese subjects. Pharm Res 2001;18:1400-4.

60 Ameyaw MM, Regateiro F, Li T, et al. MDR1 pharmacogenetics: frequency of the C $3435 \mathrm{~T}$ mutation in exon 26 is significantly influenced by ethnicity. Pharmacogenetics $2001 ; 11: 217-21$.

61 McLeod H. Pharmacogenetic differences in ethnic groups. Lancet 2002;359:78.

62 Schaeffeler E, Eichelbaum M, Brinkmann U, et al. Frequency of C3435T polymorphism of MDR I gene in African people. Lancet $2001 \cdot 358: 383-4$

$63 \mathrm{Kim}$ RB, Leake BF, Choo EF, et al. Identification of functionally variant MDR 1 alleles among European Americans and African Americans. Clin Pharmacol Ther 2001;70:189-99.

64 Fellay J, Marzolini C, Back DJ, et al, for the Swiss HIV Cohort Study. Differences in response to antiretroviral therapy in HIV-infected individuals carrying allelic variants of the multidrug resistance transporter MDR 1. Lancet 2002;359:30-6.

65 Liggett SB. beta(2)-adrenergic receptor pharmacogenetics. Am J Respir Crit Care Med 2000;161:S197-201.

66 Jacobsen P, Rossing K, Rossing P, et al. Angiotensin converting enzyme gene polymorphism and ACE inhibition in diabetic nephropathy. Kidney Int 1998;53:1002-6.

67 Ballantyne CM, Herd JA, Stein EA, et al. Apolipoprotein E genotypes and response of plasma lipids and progression-regression of coronary atherosclerosis to lipid-lowering drug therapy. J Am Coll Cardiol 2000;5: 1572-8

68 Lima JJ, Thomason DB, Mohamed MH, et al. Impact of genetic polymorphisms of the beta2-adrenergic receptor on albuterol bronchodilator pharmacodynamics. Clin Pharmacol Ther 1999;5:519-25

69 Israel E, Drazen JM, Liggett SB, et al. Effect of polymorphism of the beta(2)-adrenergic receptor on response to regular use of albuterol in asthma. Int Arch Allergy Immunol 2001;124:183-6.

70 Drysdale CM, McGraw DW, Stack CB, et al. Complex promoter and coding region beta 2-adrenergic receptor haplotypes alter receptor expression and predict in vivo responsiveness. Proc Natl Acad Sci USA 2000;97:10483-8

71 McDonald OG, Krynetski EY, Evans WE. Molecular haplotyping of genomic DNA for multiple single nucleotide polymorphisms located kilobases apart, using long-range PCR and intramolecular ligation. Pharmacogenetics 2002;12:1-7.

72 Evans WE, McLeod HL. Pharmacogenomics: drug disposition, drug targets and side effects. N Engl J Med 2003;348:538-49.

73 Arranz MJ, Munro J, Birkett J, et al. Pharmacogenetic prediction of clozapine response. Lancet 2000;355:1615-16.

74 Phillips KA, Vennstra DL, Oren E, et al. Potential role of pharmacogenomics in reducing adverse drug reastions: a systematic review. JAMA 2001;286:2270-9.

75 Meyer UA. Pharmacogenetics and adverse drug reactions. Lancet 2000;356:1667-71

76 Aithal GP, Day CP, Kesteven PJ, et al. Association of polymorphisms in the cytochrome P450 CYP2C9 with warfarin dose requirement and risk of bleeding complications. Lancet 1999;353:717-19.

77 Furuya H, Fernandez-Salguero P, Gregory W, et al. Genetic polymorphism of CYP2C9 and its effect on warfarin maintenance dose requirement in patients undergoing anticoagulation therapy. Pharmacogenetics 1995:5:389-92.

78 Steward DJ, Haining RL, Henne KR, et al. Genetic association between sensitivity to warfarin and expression of CYP2C9*3. Pharmacogenetics 1997; 7:361-7

79 Taube J, Halsall D, Baglin T. Influence of cytochrome P-450 CYP2C9 polymorphisms on warfarin sensitivity and risk of over-anticoagulation in patients on long-term treatment. Blood 2000;96:1816-19.

80 Furuta T, Ohashi K, Kamata T, et al. Effect of genetic differences in omeprazole metabolism on cure rates for Helicobacter pylori infection and peptic ulcer. Ann Intern Med 1998;129:1027-30.

81 Goldstein JA, Faletto MB, Romkes-Sparks M, et al. Evidence that CYP2C19 is the major (S) mephentoin 4'-hydroxylase in humans. Biochemistry 1994;33: 1743-52.
82 Brosen K. Clinical significance of the sparteine/debrisoquine oxidation polymorphism. Eur J Clin Pharmacol 1989;36:537-47.

83 Caraco Y, Sheller J, Wood AJ. Pharmacogenetic determination of the effects of codeine and prediction of drug interactions. J Pharmacol Exp Ther 1996;278:1165-74.

84 Dahl ML, Bertilsson L. Genetically variable metabolism of antidepressants and neuroleptic drugs in man. Pharmacogenetics 1993:3:61-70.

85 Desmeules J, Gascon MP, et al. Impact of environmental and genetic factors on codeine analgesia. Eur J Clin Pharmacol 1991;41:23-6.

86 Kapitany T, Meszaros K, Lenzinger E, et al. Genetic polymorphisms for drug metabolism (CYP2D6) and tardive dyskinesia in schizophrenia. Schizophr Res 1998;32:101-6.

87 Lee JT, Kroemer HK, Silberstein DJ, et al. The role of genetically determined polymorphic drug metabolism in the beta-blockade produced by propafenone. N Engl J Med 1990;322:1764-8.

88 Lennard MS, Tucker GT, Silas JH, et al. Differential stereoselective metabolism of metoprolol in extensive and poor debrisoquin metabolizers. Clin Pharmacol Ther 1983;34:732-7.

89 Poulsen L, Brosen K, Arendt-Nielsen L, et al. Codeine and morphine in extensive and poor metabolizers of sparteine: pharmacokinetics, analgesic effect and side effects. Eur J Clin Pharmacol 1996;51:289-95.

90 Sallee FR, DeVane CL, Ferrell RE. Fluoxetine-related death in a child with cytochrome P-450 2D6 genetic deficiency. J Child Adolesc Psychopharmacol 2000;10:27-34.

91 Sindrup SH, Poulsen L, Brosen K, et al. Are poor metabolisers of sparteine/debrisoquine less pain tolerant than extensive metabolisers? Pain 1993:53:335-9

92 Tyndale RF, Droll KP, Sellers EM. Genetically deficient CYP2D6 metabolism provides protection against oral opiate dependence. Pharmacogenetics 1997; 7:375-9.

93 Zhou HH, Koshakji RP, Silberstein DJ, et al. Altered sensitivity to and clearance of propranolol in men of Chinese descent as compared with American whites. N Engl J Med 1989;320:565-70.

94 Felix CA, Walker AH, Lange BJ, et al. Association of CYP3A4 genotype with treatment-related leukemia. Proc Natl Acad Sci USA 1998;95:13176-81.

95 Kuehl P, Zhang J, Lin Y, et al. The CYP3A promoters: DNA sequence diversity and concordance of one allele with polymorphic CYP3A5 expression. Nat Genet 2001;27:383-91.

96 Rebbeck TR, Jaffe JM, Walker AH, et al. Modification of clinical presentation of prostate tumors by a novel genetic variant in CYP3A4. J Natl Cancer Inst 1998:90:1225-9.

97 Sata F, Sapone A, Elizondo G, et al. CYP3A4 allelic variants with amino acid substitutions in exon 7 and 12: Evidence for an allelic variant with altered catalytic activity. Clin Pharmacol Ther 2000;67:48-56.

98 Diasio RB, Beavers TL, Carpenter JT. Familial deficiency of dihydropyrimidine dehydrogenase. Biochemical basis for familial pyrimidinemia and severe 5- fluorouracil-induced toxicity. J Clin Invest 1988:81:47-51.

99 Gonzalez FJ, Fernandez-Salguero P. Diagnostic analysis, clinical importance and molecular basis of dihydropyrimidine dehydrogenase deficiency. Trends Pharmacol Sci 1995;16:325-7.

100 Blum M, Demierre A, Grant DM, et al. Molecular mechanism of slow acetylation of drugs and carcinogens in humans. Proc Natl Acad Sci USA 1991;88:5237-41.

101 Evans DAP, Manley KA, McKusick VA. Genetic control of isoniazid metabolism in man. BM 1960;2:485-91.

102 Grant DM, Hughes NC, Janezic SA, et al. Human acetyltransferase polymorphisms. Mutat Res 1997;376:61-70.

103 Hughes HB, Biehl JP, Jones AP, et al. Metabolism of isoniazid in man as related to occurrence of peripheral neuritis. Am Rev Tuberc 1954;70:266-73

104 Nakamura $\mathbf{H}$, Uetrecht J, Cribb AE, et al. In vitro formation, disposition and toxicity of $\mathrm{N}$-acetoxy-sulfamethoxazole, a potential mediator of sulfamethoxazole toxicity. J Pharmacol Exp Ther 1995;274:1099-104.

105 Spielberg SP. N-acetyltransferases: pharmacogenetics and clinical consequences of polymorphic drug metabolism. J Pharmacokinet Biopharm 1996:24:509-19.

106 Aarbakke J, Janka-Schaub G, Elion GB. Thiopurine biology and pharmacology. Trends Pharmacol Sci 1997;18:3-7.

107 Black AJ, McLeod HL, Capell HA, et al. Thiopurine methyltransferase genotype predicts therapy-limiting severe toxicity from azathioprine. Ann Intern Med 1998;129:716-18

108 Evans WE, Horner M, Chu YQ, et al. Altered mercaptopurine metabolism, toxic effects, and dosage requirement in a thiopurine methyltransferase-deficient child with acute lymphocytic leukemia. J Pediatr 1991;119:985-9.

109 Krynetski EY, Evans WE. Pharmacogenetics of cancer therapy: getting personal. Am J Hum Genet 1998;63:11-16.

110 Lennard L. Clinical implications of thiopurine methyltransferaseoptimization of drug dosage and potential drug interactions. Ther Drug Monit 1998;20:527-31

111 Lennard L, Van Loon JA, Lilleyman JS, et al. Thiopurine pharmacogenetics in leukemia: correlation of erythrocyte thiopurine methyltransferase activity and 6 - thioguanine nucleotide concentrations. Clin Pharmacol Ther 1987:41:18-25.

112 Relling MV, Hancock ML, Boyett JM, et al. Prognostic importance of 6-mercaptopurine dose intensity in acute lymphoblastic leukemia. Blood 1999;93:2817-23.

113 Relling MV, Hancock ML, Rivera GK, et al. Mercaptopurine therapy intolerance and heterozygosity at the thiopurine S-methyltransferase gene locus. J Natl Cancer Inst 1999;91:2001-8. 
114 Relling MV, Rubnitz JE, Rivera GK, et al. High incidence of 5 secondary brain tumours after radiotherapy and antimetabolites. Lancet 1999;354:34-9.

115 Schuetz E, Gummert J, Mohr F, et al. Azathioprine-induced myelosuppression in thiopurine methyltransferase deficient heart transplant recipient. Lancet 1993;341:436.

116 Wormhoudt LW, Commandeur JN, Vermeulen NP. Genetic polymorphisms of human $\mathrm{N}$-etyltransferase, cytochrome P450 glutathione-S-transferase, and epoxide hydrolase enzymes: relevance to xenobiotic metabolism and toxicity. Crit Rev Toxicol 1999;29:59-124.

117 Kohno M, Yokokawa K, Minami M, et al. Association between angiotensin-converting enzyme gene polymorphisms and regression of left ventricular hypertrophy in patients treated with angiotensin-converting enzyme inhibitors. Am J Med 1999;106:544-9.

118 Ohmichi N, Iwai N, Uchida Y, et al. Relationship between the response to the angiotensin converting enzyme inhibitor imidapril and the angiotensin converting enzyme genotype. Am J Hypertens 1997; 10:951-5.

119 Okamura A, Ohishi M, Rakugi $H$, et al. Pharmacogenetic analysis of the effect of angiotensin-converting enzyme inhibitor on restenosis after percutaneous transluminal coronary angioplasty. Angiology 1999;50:811-22.

120 Penno G. Effect of angiotensin-converting enzyme (ACE) gene polymorphism on progression of renal disease and the influence of $A C E$ inhibition in IDDM patients: findings from the EUCLID randomized controlled trial. EURODIAB Controlled Trial of Lisinopril in IDDM. Diabetes 1998;47:1507-11.

121 Perna A, Ruggenenti P, Testa A, et al. ACE genotype and ACE inhibitors induced renoprotection in chronic proteinuric nephropathies 1 . Kidney Int 2000;57:274-81.

122 Prasad A, Narayanan S, Husain S, et al. Insertion-deletion polymorphism of the ACE gene modulates reversibility of endothelial dysfunction with ACE inhibition. Circulation 2000;102:35-41.

123 Sasaki $M$, Oki T, luchi $A$, et al. Relationship between the angiotensin converting enzyme gene polymorphism and the effects of enalapril on left ventricular hypertrophy and impaired diastolic filling in essential hypertension: $M$ - mode and pulsed Doppler echocardiographic studies. Hypertens 1996;14:1403-08.

124 Stavroulakis GA, Makris TK, Krespi PG, et al. Predicting response to chronic antihypertensive treatment with fosinopril: the role of angiotensin-converting enzyme gene polymorphism. Cardiovasc Drugs Ther 2000; 14:427-32.

125 Marian AJ, Safavi F, Ferlic L, Dunn JK, et al. Interactions between angiotensin-l converting enzyme insertion/deletion polymorphism and response of plasma lipids and coronary atherosclerosis to treatment with fluvastatin: the lipoprotein and coronary atherosclerosis study. J Am Coll Cardiol 2000;35:89-95

126 Cockcroft JR, Gazis AG, Cross DJ, et al. Beta(2)-adrenoceptor polymorphism determines vascular reactivity in humans. Hypertension 2000;36:371-5.

127 Gratze G, Fortin J, Labugger R, et al. beta-2 Adrenergic receptor variants affect resting blood pressure and agonist-induced vasodilation in young adult Caucasians. Hypertension 1999;33:1425-30.

128 Hoit BD, Suresh DP, Craft L, et al. beta2-adrenergic receptor polymorphisms at amino acid 16 differentially influence agonist-stimulated blood pressure and peripheral blood flow in normal individuals. Am Heart J 2000;139:537-42.

129 Martinez FD, Graves PE, Baldini M, et al. Association between genetic polymorphisms of the beta2-adrenoceptor and response to albuterol in children with and without a history of wheezing. J Clin Invest 1997; 100:3184-8.
130 Tan S. Association between beta 2-adrenoceptor polymorphism and susceptibility to bronchodilator desensitisation in moderately severe stable asthmatics. Lancet 1997;350:995-9.

131 Jia $\mathbf{H}$, Hingorani $A D$, Sharma $P$, et al. Association of the $G(s)$ alpha gene with essential hypertension and response to beta-blockade. Hypertension 1999:34:8-14.

132 Brandt JT, Isenhart CE, Osborne JM, et al. On the role of platelet Fc gamma Rlla phenotype in heparin-induced thrombocytopenia. Thromb gamma Rlla phenotype in hepar
Haemost 1995;74:1564-72.

133 Ongphiphadhanakul B, Chanprasertyothin S, Payatikul P, et al. Oestrogen-receptor-alpha gene polymorphism affects response in bone mineral density to oestrogen in post-menopausal women. Clin Endocrinol (Oxf) 2000;52:581-5.

134 Hansen T, Echwald SM, Hansen L, et al. Decreased tolbutamide-stimulated insulin secretion in healthy subjects with sequence variants in the high-affinity sulfonylurea receptor gene. Diabetes 1998;47:598-605

135 Basile VS, Masellis M, Badri F, et al. Association of the Mscl polymorphism of the dopamine D3 receptor gene with tardive dyskinesia in schizophrenia. Neuropsychopharmacology 1999;21:17-27.

136 Cohen BM, Ennulat DJ, Centorrino F, et al. Polymorphisms of the dopamine D4 receptor and response to antipsychotic drugs. Psychopharmacology (Berl) 1999;141:6-10.

137 Eichhammer $\mathbf{P}$, Albus $M$, Borrmann-Hassenbach $M$, et al. Association of dopamine D3-receptor gene variants with neuroleptic induced akathisia in schizophrenic patients: a generalization of Steen's study on DRD3 and in schizophrenic patients: a generalization of Steen's study
tardive dyskinesia. Am J Med Genet 2000;96:187-91.

138 Hwu HG, Hong CJ, Lee YL, et al. Dopamine D4 receptor gene polymorphisms and neuroleptic response in schizophrenia. Biol Psychiatr 1998;44:483-7.

139 Kaiser R, Konneker M, Henneken M, et al. Dopamine D4 receptor 48-bp repeat polymorphism: no association with response to antipsychotic treatment, but association with catatonic schizophrenia. Mol Psychiatr 2000;5:418-24

140 Scharfetter J, Chaudhry HR, Hornik K, et al. Dopamine D3 receptor gene polymorphism and response to clozapine in schizophrenic Pakistani patients. Eur Neuropsychopharmacol 1999;10:17-20.

141 Suzuki A Mihara K, Kondo T, et al. The relationship between dopamine D2 receptor polymorphism at the Taq $1 \mathrm{~A}$ locus and therapeutic response to nemonapride, a selective dopamine antagonist, in schizophrenic patients. Pharmacogenetics 2000; 10:335-41

142 Joober $\mathbf{R}$, Benkelfat $C$, Brisebois K, et al. T102C polymorphism in the 5 HT2A gene and schizophrenia: relation to phenotype and drug response variability. J Psychiatr Neurosci 1999:24:141-6.

143 Masellis M, Basile V, Meltzer HY, et al. Serotonin subtype 2 receptor genes and clinical response to clozapine in schizophrenia patients. Neuropsychopharmacology 1998;19:123-32.

144 Yu YW, Tsai SJ, Lin CH, et al. Serotonin-6 receptor variant (C267T) and clinical response to clozapine. Neuroreport 1999;10:1231-3.

145 Zill P, Baghai TC, Zwanzger $P$, et al. Evidence for an association between a $G$-protein beta3-gene variant with depression and response to antidepressant treatment. Neuroreport 2000;11:1893.

$146 \mathrm{Kim}$ DK, Lim SW, Lee S, et al. Serotonin transporter gene polymorphism and antidepressant response. Neuroreport 2000;11:215-19.

147 Smeraldi E, Zanardi R, Benedetti F, et al. Polymorphism within the promoter of the serotonin transporter gene and antidepressant efficacy of fluvoxamine. Mol Psychiatr 1998;3:508-11

148 Whale R, Quested DJ, Laver D, et al. Serotonin transporter (5-HTT) promoter genotype may influence the prolactin response to clomipramine. Psychopharmacology (Berl) 2000;150:120-2.

149 McCarthy TV, Quane KA, Lynch PJ. Ryanodine receptor mutations in malignant hyperthermia and central core disease. Hum Mutat 2000;15:410-17. 